\title{
CRISE ECONÔMICA E PROTESTO GLOBAL: A ATUALIDADE DE ROSA LUXEMBURGO
}

\author{
ECONOMIC CRISIS AND GLOBAL PROTEST: THE ACTUALITY OF \\ ROSA LUXEMBURGO
}

DOI: http://dx.doi.org/10.5380/cg.v9i1.69851

\section{Mateus Coelho Martins de Albuquerque ${ }^{1}$}

\begin{abstract}
Resumo
Este artigo tem por objetivo discutir a aplicação na atualidade da obra da filósofa, economista e militante revolucionária polonesa Rosa Luxemburgo (1871-1919). A hipótese levantada é a de que a autora se faz atual em dois eixos: na insuficiência das reformas para a emancipação da humanidade em sociedades capitalistas e na necessidade construir movimentos revolucionários radicais, internacionalizados e com constante relação entre a base e a vanguarda. No primeiro eixo, o debate da autora com Eduard Bernstein, na obra "Reforma ou Revolução?” (2015) é colocado em paralelo com o processo de esgotamento da social-democracia, a ascensão do neoliberalismo e a consequente crise econômica de 2008. No segundo eixo, os debates de Rosa Luxemburgo com os revolucionários da II Internacional (como Kautsky e Lenin) são comparados ao que a sociologia contemporânea tem a dizer sobre os chamados "novíssimos movimentos sociais" do período póscrise. A conclusão do trabalho é a de que os paralelos bibliográficos indicam que a obra de Luxemburgo é extremamente atual e relevante para aqueles que querem compreender o capitalismo do século XXI e seus conflitos.
\end{abstract}

Palavras-Chave: Rosa Luxemburgo; Crise Econômica; Protesto.

\begin{abstract}
This article aims to discuss the current application of the work of the polish philosopher, economist and revolutionary militant Rosa Luxemburg (1871-1919). The hypothesis raised is that the author is relevant in two axes: the insufficiency of reforms for the emancipation of humanity in capitalist societies and the need to build radical, internationalized revolutionary movements with a constant relationship between the base and the vanguard. In the first line, the author's debate with Eduard Bernstein in the book "Reform or Revolution?" (2015) is paralleled by the process of exhaustion of social democracy, the rise of neoliberalism and the consequent economic crisis of 2008. On the second axis, Rosa Luxemburg's debates with the revolutionaries of the Second International (like Kautsky and Lenin) are compared to what contemporary sociology has to say about the so-called "newer social movements" of the post-crisis period. The conclusion of the work is that the bibliographical parallels indicate that the work of Luxembourg is extremely current and relevant to those who want to understand 21th century capitalism and its conflicts.
\end{abstract}

Keywords: Rosa Luxemburgo; Economic Crisis; Protest.

\section{INTRODUÇÃO}

No ano de 2015, o Journal of Democracy, relevante periódico no campo da Ciência Política, publicou um dossiê que tinha, por tema, a seguinte pergunta: estaria a democracia em declínio? Os

\footnotetext{
${ }^{1}$ Doutorando pelo Programa de Pós-Graduação em Ciência Política da Universidade Federal do Paraná (PRPPG-UFPR), Curitiba, Paraná, Brasil. E-mail: mateusmartinsdealbuquerque@gmail.com. ORCID: https://orcid.org/oooo-0003-3015-2227.
} 
artigos ali publicados articularam em torno desta temática sob diversas óticas, apresentando os elementos que fundamentariam empiricamente esta dúvida. Um dos mais bem sucedidos - no sentido de ilustrar melhor - nesta empreitada foi o artigo Facing Up To The Democracy Recession, do pesquisador americano Larry Diamond (2015). No artigo, fazendo uso de dados da Freedom House $^{2}$ o pesquisador apresenta os quatro pontos pelos quais é possível se visualizar essa crise na democracia: uma acentuada queda na liberdade individual, crescentes processos de desdemocratização nos países em desenvolvimento, a baixa crença na democracia em países democratizados e desenvolvidos e uma crescente de regimes autoritários pelo mundo. A "quarta onda da democracia" não teria sido então tão bem sucedida.

O autor fecha seu artigo de maneira otimista: a democracia ainda é o modelo global de governança, enquanto todos os regimes autoritários seguem sob a sombra da instabilidade. Na mesma edição, Fukuyama (2015) faz seus apontamentos, não tanto através dos sintomas que formam o diagnóstico, e sim pelo diagnóstico em si. Para ele, a causa formadora do problema é a incapacidade das democracias de gerarem bons governos. A capacidade de um Estado em ser eficiente em suas múltiplas funções (de controlar a rota de aeronaves até produzir estatísticas, nas palavras do autor) é mais relevante para a consolidação de uma democracia após a ruptura com um governo autoritário que o combate à corrupção e a transparência, por exemplo. O Estado tem que ser eficaz em suas tarefas e garantir que a lei não seja meramente decorativa, mesmo que faça uso de força para se consolidar. Trazer à democracia seria uma tarefa relativamente mais simples que consolidar a democracia.

As análises de Fukuyama e Diamond possuem uma coisa em comum: ambas desconsideram a existência de uma crise econômica global no ano de 2008. As relações entre crise econômica e democracia são um rico objeto de estudo. Para estudá-las, porém, é necessária uma compreensão de democracia que ultrapasse as instâncias formais. Os efeitos da crise econômica são sentidos na política institucional, mas também tem reflexo nas ruas, no exercício da contestação pública. A forma e a intensidade de uma crise econômica têm papel preponderante na forma e na intensidade que se darão as manifestações públicas seguintes. Assim, é também tarefa da Ciência Política buscar os efeitos da crise econômica na ação coletiva. E, identificar qual a relação desta ação coletiva com a crise democrática no Século XXI.

Nesse sentido, Rosa Luxemburgo fornece caminhos instigantes para a análise. Nascida na Polônia em 1871, o ano da Comuna de Paris, Rosa emigra para Zurique em 1888. Na Suíça, realiza o seu doutoramento em Ciência Política e entra em contato com a teoria marxista, através de teóricos russos emigrados, como Plekhanov. Ao mudar-se para a Alemanha em 1897, Rosa começa a travar algumas das mais interessantes batalhas teóricas e práticas do marxismo. Encontra como

${ }^{2} \mathrm{O}$ autor aponta críticas ao método de coleta da $\mathrm{FH}$, e por isso, no artigo aqui citado, realiza algumas "correções de rumo" nestes dados. 
adversário, em primeiro lugar, o dirigente do PSDA ${ }^{3}$ Eduard Berstein, ao refutar a tese de que o partido deveria abandonar a necessidade de uma revolução socialista e buscar constantes reformas sociais. Em 1918, o antigo aliado Kautsky torna-se adversário, na urgência de defender o caráter necessário da Revolução que havia ocorrido na Rússia no ano anterior. Aliás, mesmo esse levante não passa incólume: muito do que há de mais relevante na literatura política de Rosa Luxemburgo se concentra em críticas a determinadas práticas e métodos dos bolcheviques russos.

A revolução como necessidade da classe trabalhadora na posição em que ela se encontra na economia global. O capitalismo como uma espécie de "bomba-relógio" prestes a implodir em crise. O partido revolucionário como o produto da organização política das massas, e não a organização política das massas como produto do partido revolucionário. Estes são alguns dos conceitos que foram arquitetados na literatura através destes debates, e formam o que costuma se identificar primariamente com o pensamento político e econômico de Rosa Luxemburgo. Este artigo possui dois objetivos. O primeiro é relacionar as reflexões de Rosa Luxemburgo sobre a impossibilidade de reformar o capitalismo e a urgência da revolução com as razões pelas quais a social-democracia, consolidada como modelo econômico hegemônico do chamado "primeiro mundo" durante o século XX, culminaria no neoliberalismo e na Crise Econômica de 2008. O segundo envolve relacionar a literatura de Rosa Luxemburgo sobre a organização da classe trabalhadora, passando pela sua leitura sobre o partido revolucionário, com os estudos sobre os chamados "novíssimos movimentos sociais" por parte da sociologia contemporânea. Apesar de aqui estarem separados em itens, é importante ressaltar o caráter ontológico dessas reflexões: a urgência da revolução frente a decadência do capitalismo e a necessidade de organizações plurais e dinâmicas, nunca afastados da base proletária, formam um todo coeso, uma relação de causa e consequência, no pensamento de Rosa Luxemburgo e na tradição marxista como um todo.

\section{INSUFICIÊNCIAS DA SOCIAL-DEMOCRACIA E CRISE ECONÔMICA: A REVOLUÇÃO COMO URGÊNCIA}

A desconexão entre política e economia nos trabalhos de Diamond e Fukuyama citados na introdução não é um descuido, mas uma linha epistemológica. A transformação do Estado em um grande gestor é um dos aspectos mais definitivos da leitura liberal da política; aquela, usando os termos de Bobbio (1991), que é universalizada e não-histórica, ou seja, isolada dos contextos formativos das estruturas sociais. Boron (1991) aponta as relações notáveis entre o pensamento econômico de Friedman e o choque político neoliberal: quando se pensa na moeda como uma dimensão neutra, que não produz valor, não está se pensando apenas em macroeconomia, e sim no não uso político da produção de riquezas. Assim, para o autor, a análise da política que ignora a

\footnotetext{
3 Partido Social-Democrata Alemão.
} 
perspectiva econômica é uma análise da política que abandona a construção da democracia como um valor ético e que tem que produzir necessariamente bem estar, para a discussão meramente formal. A questão que Boron (1991) nos propõem é a de que de nada adianta tratar a democracia como exigência última da sociedade quando ela, em si, não produz valor substancial.

O livro “Reforma ou Revolução?” (2015) é um dos mais reconhecidos esforços de Rosa Luxemburgo em aliar a análise econômica à prática política. Nessa obra, Rosa polemiza com Eduard Berstein e suas teses, as quais demonstram que, devido a uma adaptação do capitalismo, a revolução socialista não seria mais possível. O caminho que o Partido deveria então tomar era o de buscar reformas sociais. Mas quais eram os elementos que Bernstein apontava como fulcrais para perceber essa readequação do capitalismo? Esses eram o crédito, as associações patronais e o fim das empresas médias. Rosa trata de rebater cada um desses elementos. O crédito amplia a capacidade produtiva, mas gera conflitos de interesses entre as forças contraditórias do capitalismo (LUXEMBURGO, 2015, p.32). O mesmo ocorre com as associações patronais, que na análise de Bernstein demonstram uma supressão dos conflitos burgueses, encontram o fim desta harmonia quando o preço estabelecido por um cartel passa a atrapalhar o estabelecimento de preço de outro cartel. (LUXEMBURGO, 2015, p.34). E as empresas médias, berço criativo do capitalismo, estariam sendo extintas não porque estavam crescendo, mas porque o processo acumulador do capital tende a fundir as empresas em grandes conglomerados até a vindoura, segundo Rosa, crise de produção (LUXEMBURGO, 2015, p.40).

E, para o caso da readaptação do capital, quais deveriam ser as reformas prioritárias que o partido deveria seguir, segundo Kautsky? O fortalecimento da estrutura sindical, uma delas, levaria ao corporativismo sem uma perspectiva revolucionária. Se o sindicato não pretende romper com o capitalismo e tenciona apenas negociar melhor pagamento pelas horas de trabalho dedicadas na produção, ele distorce a correlação de forças: deixa-se de falar em um conflito entre o proletariado e a burguesia, e começa-se a se falar em um conflito entre trabalhadores e patrões contra o consumidor, que quer pagar menos pelos produtos (LUXEMBURGO, 2015, p.90). A outra proposta, a do fortalecimento do cooperativismo, careceria de funcionalidade no capitalismo, já que a produção cooperada precisa de uma cooperativa de consumo para poder projetar as demandas produtivas. Como isso é impossível em larga escala neste modo de produção, o cooperativismo só compete com o modelo desordenado e caótico do capitalismo na pequena e média esfera (LUXEMBURGO, 2015, p.86). Kautsky propõem também o fortalecimento das instâncias democráticas, o que para Rosa é disfuncional: o capitalismo abre mão da democracia quando convém. Ao mostrar que a renúncia da revolução contribui para o desenvolvimento da democracia burguesa, Kautsky estaria, na verdade, demonstrando a volatilidade dessa democracia e a necessidade de construir outra (LUXEMBURGO, 2015, p.97).

A Teoria da Adaptação de Kautsky foi linha prática adotada pelo PSDA, mas acabou sendo derrubada pelas circunstâncias históricas alguns anos depois. Em 1914, o mundo se lançaria em um 
amplo conflito bélico de proporções nunca antes vistas, sustentado pelos interesses imperialistas. Uma década após o fim desta guerra, o capitalismo financeiro descontrolado estouraria em uma crise sem precedentes até então, em 1929. Mas a Teoria da Catástrofe eminente do capitalismo de Rosa também não se confirmaria, pelo menos não brevemente. A guerra e a crise não levaram a extinção do capitalismo. Ele se reconfiguraria, no século XX, em um Estado de Bem-Estar Social, extremamente sustentado nas ideias do economista inglês John Maynard Keynes. Mas o mundo iria descobrir a existência de limites na extensão desse bem-estar social conciliado com o capitalismo.

Importante ressaltar, como destaca Mandel (1971), que a estratégia social-democrata foi hegemônica na Segunda Internacional, tendo sido defendida, inclusive, por Friedrich Engels. A crise econômica de 1929 possui o importante papel de limitar esse tipo de visão, ao confirmar que há sim um catastrofismo eminente ao capitalismo. Os méritos de Rosa Luxemburgo no que concernem a esse ponto em específico estão circunscritos no fato de ela ter produzido uma leitura contrária ao hegemonismo presente na Internacional de maneira anterior ao grosso de seus militantes, já em 1914. Esse reconhecimento vindo de Mandel é relevante, já que o próprio autor, em seu livro "Capitalismo Tardio" (1982) apostou, corretamente, que o Estado de Bem-Estar Social encontraria seu esgotamento, através de um aumento vertiginoso da superprodução que levaria a uma transferência do trabalho para atividades terciárias, mais facilmente substituíveis através do aumento do estoque de desemprego. A concepção de inevitabilidade de implosão do sistema, mesmo em seus "anos dourados", é continuidade do pensamento de Rosa Luxemburgo em Ernest Mandel.

Przeworski e Wallerstein (1988) já punham o problema na perspectiva da Ciência Política, mais especificamente no campo da Economia Política. A combinação do capitalismo com a democracia funciona como uma espécie de acordo, que os que detêm os meios de produção oferecem participação política em troca da permanência da propriedade privada como instituto socialmente aceito. O keynesianismo e o Estado de Bem-Estar Social funcionam como amortecedores dos conflitos gerados nesse acordo, garantindo ganhos (mesmo que desproporcionais) a todos. Os autores atribuem a Keynes o fornecimento dos valores ideológicos que sustentam as relações político-econômicas das democracias capitalistas modernas. Esse compromisso só se sustentava enquanto produzia emprego e renda para a população, enquanto garantia do mínimo de subsistência, mesmo perpassando por diversas relações corporativistas dos entes privados instalados no Estado, guinando tendenciosamente o impulsionamento e o financiamento público dessa economia.

O modelo keynesiano, sustentado na constante geração de demanda, sustenta-se como um modelo de curto prazo, de ciclos curtos e constantes. O constante aumento de demanda tende a reduzir a capacidade de poupança, o que não apresenta problemas com a economia funcionando abaixo do máximo, mas reduz a capacidade de reinvestimento no pleno emprego. A burguesia, por 
sua vez, atua no campo da oferta, já que amplia seu capital através do lucro. Para a burguesia, a demanda que se ajuste ao lucro da oferta. A redução das poupanças e a crise fiscal dos anos 70 consolidaram o arcabouço argumentativo para uma nova forma de sociedade, intitulada neoliberal, que tira do Estado o "monopólio do contrato" de regulação. As regras de mercado passam a mediar as relações humanas, e devem ser protegidas, inclusive, pela força do próprio Estado. Sem mais a entrega do bem-estar, cai em declínio o acordo. A democracia perde sua mediação e, com isso, seu crédito.

\begin{abstract}
O momento atual, contudo, é o primeiro desde os anos 20 em que os proprietários de capital rejeitam abertamente um compromisso que envolva a influência pública sobre o investimento e a distribuição da renda. Pela primeira vez em muitas décadas, a direita tem um projeto histórico próprio: libertar a acumulação de todas as cadeias impostas a ela pela democracia. Pois a burguesia jamais completou sua revolução. Logo que libertou a acumulação das amarras impostas pela ordem feudal, a burguesia foi forçada a sujeitá-la às limitações do controle popular exercido por meio do sufrágio universal. A combinação da propriedade privada dos meios de produção com o sufrágio universal é um compromisso, e ele implica que a lógica da acumulação não seja exclusivamente a lógica dos atores privados. O que está envolvido na atual ofensiva de direita não é simplesmente uma questão de impostos, gastos de governo, ou mesmo distribuição da renda. Os planos para abrandar a tributação dos lucros, abolir os controles ambientais, eliminar os programas previdenciários, acabar com o controle do governo sobre a segurança dos produtos e as condições de trabalho e para enfraquecer os sindicatos são muito mais do que uma reorientação da política econômica. Constituem um projeto para uma nova sociedade, uma revolução burguesa. (PZEWORSKI; WALLERSTEIN, 1988, p.44)
\end{abstract}

O esgotamento dese modelo tem por consequência amplo aumento nas desigualdades sociais. Piketty (2013) demonstra em seu estudo que a redução da concentração de renda dos capitais nos anos 50/60 representou um interregno, criado a partir de um contexto histórico específico, no desenvolvimento do capitalismo. A partir da década de 70, a concentração de renda e a crescente desigualdade voltam a crescer, seguindo o padrão estabelecido pelo capitalismo da Revolução Industrial. Essa percepção abre espaço para duas importantes conclusões. A primeira é a de que a ideia de que os aspectos concentradores do capitalismo das primeiras décadas não eram frutos de certo caráter embrionário deste capitalismo, e sim a forma de capitalismo mais comum ao longo da história - excluindo os tais "anos dourados" dos anos 50/60. A segunda é a de que não existe um "movimento natural”, imutável, impossível de ser contido, da forma como se dá a circulação de bens no globo, ela pode ser consideravelmente alterada em sua configuração se políticas públicas ou mudanças sócio históricas forem operadas para esse fim.

Desde os anos 70, o mundo vive uma grande concentração de riquezas, também comprovada em Pikkety (2013). Esse número não chega ao mesmo nível da Revolução Industrial, tanto pelo advento do imposto de renda, quanto pela queima de poupança dos herdeiros durante os anos 50/60. Isso se dá principalmente pela relação matemática em que o crescimento da renda do capital é superior ao crescimento dos países. Assim, independente do grau de recessão 
abordado, os que acumularam capital através de um determinado processo histórico seguem vivendo apenas deste capital. Este capital se metamorfoseou de sociedades agrícolas e títulos de dívida pública para estruturas mais complexas, como imóveis e ações. Cresce em velocidade consideravelmente maior e mais desigual que as desigualdades de renda-trabalho (em exemplo trazido pelo autor, a diferença de renda-capital na Suécia, um dos países menos desiguais do mundo, é maior que a diferença da renda-salário nos Estados Unidos, um dos mais desiguais).

Um dos principais problemas epistemológicos de Bernstein, na análise de Rosa, é o fato de o teórico alemão pensar os elementos do que ele considera as razões pelas quais o capitalismo estaria se adaptando de maneira insulada, sem conectar-se com outros elementos das estruturas sociais:

Mas - sem tomar em conta o seu caráter errôneo, todos os pormenores da teoria da adaptação têm um traço característico em comum. Nessa teoria, as manifestações todas da vida econômica que acabamos de citar não são estudadas nas suas relações orgânicas com o conjunto do desenvolvimento capitalista e com todo o mecanismo econômico, e sim fora dessas relações, como disjecta membra (partes esparsas) de uma máquina sem vida. (LUXEMBURGO, 2015, p.68)

Assim, o contínuo aumento das desigualdades sociais, a falência do Estado de Bem-Estar Social e a ampliação da concentração de renda demonstram certa atualidade das reflexões de Rosa Luxemburgo, não apenas pela sua expressão nas relações econômicas, mas pela sua relação íntima com o crescente descrédito no modelo democrático, citado na introdução. Ranciére (2014), sob o prisma da filosofia política, versa sobre as causas e consequências desse ódio à democracia. A democracia contemporânea, para o autor, é uma contradição exposta. Se em parte, deflagra guerra global, seja através da moralidade ou do ataque bélico direto, a governos não democráticos, depende de um cerceamento constante da própria democracia para garantir a estabilidade de suas instituições. "A democracia moderna significa a destruição do limite político pela lei da ilimitação própria da sociedade moderna”. (RANCIÉRE, 2014, p.19). Se antes o totalitarismo (termo atribuído usualmente às experiências comunistas e ao nazi-fascismo, sem qualquer distinção, na literatura liberal) representava um Estado que, em prol de um bem maior coletivo, destruía o indivíduo, hoje os Estados democráticos assumem essas características. Essa seria a base da descrença na democracia, o fato de as pessoas não viverem de fato em uma democracia, e sim em um regime de trocas entre as oligarquias. O laissez-faire como linguagem global prometia uma maior emancipação dos indivíduos através do acumulo de capitais, mas na verdade culminou em um fortalecimento dos Estados e de seus mecanismos de coerção.

Existe uma notória relação entre as insuficiências da social-democracia, antes citadas, e o processo de acumulação neoliberal. Fiori (2001) remonta o surgimento do neoliberalismo ao fim do acordo de Bretton Woods, que permitiu uma maior circulação de capital sem lastro e a financeirização da economia através de uma política de desregulamentação. Esse processo encaminhou para uma virada ideacional, representada pelas eleições de Margareth Tatcher, no 
Reino Unido (1979), e Ronald Reagan, nos Estados Unidos (1981), e pelo Consenso de Washington no final da década de 1980. Dardot e Laval (2016) remontam o surgimento do neoliberalismo a um período anterior: os seus debates formuladores podem ser traçados desde as proposições de Spencer (fundadas no recuo dos principais pensadores do liberalismo clássico quanto à utopia o livre-mercado) até o Colóquio Walter Lippman, de 1938, que pautou a necessidade de um Estado "interventor" para garantir a livre-concorrência. Para esses autores, o neoliberalismo se configura não só como um modelo de mundo, mas como um modelo de pensamento, uma nova racionalidade. De fato, as notas precursoras dessa racionalidade estavam a circular pela academia muito antes da ascensão em si do modelo neoliberal, o que fortalece, ainda mais, a tese de que essa ascensão só foi possível, só tomou materialidade quando o modelo "intervencionista" esgotou-se em suas limitações, anteriormente apontadas por Przeworski e Wallerstein (1988).

\begin{abstract}
Em meados da década de 1960, o ciclo de crescimento do fordismo (que também pode ser compreendido por Estado do Bem Estar) começa a declinar. A queda da produtividade e lucratividade corporativas nos Estados Unidos depois de 1966 marcou o início de um problema fiscal naquele país, com consequências sobre suas políticas sociais. As fábricas instaladas em países do Terceiro Mundo conseguiam os maiores lucros em virtude da precariedade das condições de trabalho e dos baixos salários. Mas a decisão dos países da OPEP de aumentar o preço do petróleo, elevando o preço do barril de US\$ 2,90 para US\$ 11,65 em apenas três meses, em 1973 teve efeito catastrófico sobre a economia mundial. A partir de então, foi quebrada a "rigidez" do fordismo, fato que levou as empresas a adotar novas estratégias de sobrevivência (MOTA, 2013, p.54).
\end{abstract}

Em 2008, a racionalidade neoliberal alcança o seu limite de acumulação, levando para o esgotamento. A crise, iniciada nos Estados Unidos pelo excesso de emissão de subprime 4 culminou em uma recessão global sem precedentes. Segundo Mota (2013), a crise é a resposta de um sistema destinado a criar riqueza artificial, não lastreada em riqueza material, como bens e serviços. A crise, segundo o autor, provoca um enorme "custo social", por atingir, diretamente, os trabalhadores sem seguridade social ou poupança. "A parte trágica desse cassino global está no recrudescimento das desigualdades sociais e das crises cíclicas do capitalismo, trazendo diversos infortúnios a milhares de indivíduos e suas famílias” (MOTA, 2013, p.58). O período pós-crise evidenciou ainda mais o caráter de interventor pró-mercado do Estado capitalista: os esforços das nações envolvidas na crise se destinaram a salvar boa parte das instituições financeiras falidas, enquanto as populações do mundo arcavam com o ônus da crise.

Esse processo encaminhou para uma série de movimentos sustentados em uma descrença no Estado capitalista como instituição capaz de resolver os problemas da humanidade. Como dito na introdução, a análise econômica e as reflexões sobre os movimentos sociais têm conexão implícita. Cabe aqui, ao fim desse excerto, reforçar a atualidade do pensamento econômico de Rosa Luxemburgo. Em seus debates com Bernstein, já estava explicitado que o enfoque em reformas

4 Títulos de seguro lastreados na hipoteca americana. Com a insolvência do mercado imobiliário, os títulos passaram a valer nada. 
sociais - abandonando o caráter revolucionário do PSDA - não impediria o capitalismo de chegar à crise econômica e social. De fato, não impediu.

\section{O MOVIMENTO DE MASSAS INTERNACIONAL}

No já citado “Reforma ou Revolução?”, Rosa Luxemburgo apresenta um dos conflitos mais preponderantes para o entendimento do debate sobre a indignação coletiva hoje. Kautsky, ao defender o modelo de reformas, propõem uma legalidade jurídica da transformação social. Entretanto, tal ideia seria contraditória, tendo em vista que toda e qualquer opressão do capitalismo não se concentra na dimensão jurídica, mas sim, econômica. O caráter excepcional do Estado capitalista está, justamente, na equalização jurídica dos sujeitos sociais:

Como se distingue a sociedade burguesa das outras sociedades de classes - a antiga e a medieval? Precisamente no fato de não repousar hoje a dominação de classe em "direitos adquiridos", e sim em verdadeiras relações econômicas, no fato de não ser o salariato uma relação jurídica, e sim uma relação puramente econômica; Em todo o nosso sistema jurídico não se encontrará uma só fórmula de dominação da classe atual. Se ainda restam vestígios de tais fórmulas, são precisamente sobrevivências da sociedade feudal, tal como o regulamento relativo aos criados. (LUXEMBURGO, 2015, p.102)

Mas como essa desvinculação da lógica formal se relaciona em um mundo formalmente organizado? A própria separação entre os países responde a uma lógica formal, de Estados juridicamente constituídos. A luta por mudanças sociais limita-se a essa separação préestabelecida? Essa questão está bastante presente na literatura atual, dos protestos transpassando as fronteiras nacionais. Tarrow (2013), ao tratar dos aspectos transnacionais dos movimentos sociais, afirma que os indivíduos levam as questões domésticas aonde quer que estejam, e são, ao mesmo tempo, constrangidos e motivados por elas a ingressar o que é trazido de "dentro" para o que acontece "fora". A ampliação do processo de globalização e a nova dinâmica interestatal da política internacional abrem espaço para um leque ainda mais amplo de transnacionalidade, tanto nos mecanismos de contágio quanto nas próprias formas como determinadas demandas serão colocadas no enfrentamento. O que é importante notar nos escritos do autor é que essa nova configuração global não só traz novos mecanismos de luta e exposição de demanda, como também traz novos adversários e reconfigurações institucionais das forças coercitivas. Ao mesmo tempo, essa transição não é automática e as pautas locais seguem sendo relevantes, não sendo todo o movimento contra as ações do capital global um movimento globalizado, por exemplo.

Essa perspectiva encontra eco nos estudos sobre difusão de Della Porta e Mattoni (2014): os protestos se espalham de maneira internacional, mas se reconfiguram para pautas locais. Essa seria uma diferença fulcral entre os movimentos por justiça global do final do século XX e início do 
século XXI e os novíssimos movimentos sociais, pós-crise de 2008. Para as autoras, o transnacionalismo difunde práticas, ideias e imagens que podem servir (e servem) de inspiração aos ativistas ao redor do globo. Na situação de crise econômica, esse caráter transnacional se destaca, já que na forma globalizada do capital, a crise atinge a todos. Mas atinge de diferentes maneiras, em diferentes setores, em diferentes intensidades.

A crise global de 2008 provocou protestos em diversos países, como Espanha, Brasil e Estados Unidos, gerando protestos que aproveitavam do repertório do que era realizado em outros países, mas acrescentando os novos fatos da conjuntura local. Voltando para Tarrow (2013), podemos perceber a dimensão internacional como multifacetada e complexa, abrindo espaço para diversas demandas e também para reconciliações. Não é um simples espaço de interação e solidariedade, as relações não são meramente lineares. Ao mesmo tempo em que oportunidades são abertas, dificuldades são criadas pela dimensão internacional.

A questão nacional foi palco de um grande debate travado por Rosa em 1918, no seu livro “A Revolução Russa” (1991). O alvo do debate agora era o líder revolucionário russo Vladimir Lenin, já que o livro funciona, ao mesmo tempo, como elogio e crítica às táticas revolucionárias adotadas pelos bolcheviques russos, liderados por Lenin. Os bolcheviques tinham como tática dialogar com o nacionalismo, buscando a autodeterminação dos povos. Esses desejavam plebiscitos para que os países decidissem seu destino. O problema, para Rosa, é que o conceito de nação é burguês: o movimento socialista deve buscar a autodeterminação das classes.

O bolchevismo se furtou de criar uma ampla unidade contra o imperialismo, procurando tirar a Rússia automaticamente da Primeira Guerra Mundial. Para isso, pagou indenização à Alemanha e entregou a Letônia, a Estônia e a Lituânia para o imperialismo em 1918, executando, inclusive, duzentos comunistas russos que se opuseram a esse movimento. Segundo Rosa Luxemburgo, esse movimento impediu o socialismo no Ocidente. A análise de Rosa Luxemburgo apresenta certa congruência com a literatura atual: os movimentos sociais agem de maneira transnacional, rompendo os limites impostos pelas fronteiras. Entretanto, buscam certa identificação com as questões nacionais. A contemporaneidade demonstrou certa síntese dialética entre Lenin e Rosa Luxemburgo: questões e identidades limitadas ao nacional são relevantes, mas um sentimento transnacional funciona como elemento de contágio.

É importante frisar, como demonstra Mariutti (2019), que a questão internacional em Rosa Luxemburgo se diferencia através de seu olhar próprio quanto à questão do imperialismo. Ao contrário de Lenin, para Luxemburgo o imperialismo não é uma "fase" do capitalismo, mas uma dimensão inerente a sua própria constituição, mesmo primitiva. Essa diferença apresentará impactos relevantes no que concerne à visão da dominação: a guerra imperialista entre as potências é uma condição eminente, levando Luxemburgo a desenvolver o raciocínio de que qualquer apoio a um dos lados da Grande Guerra seria o apoio a uma forma própria do 
capitalismo. A crítica da teoria da revolução em Rosa Luxemburgo é internacional porque sua própria concepção de capitalismo é indissociavelmente internacional.

A explicação sobre a formação e consolidação do capitalismo na Europa fica, portanto, em segundo plano e, quando aludida, é abordada predominantemente deste ponto de vista. Logo, o alargamento sistemático e acelerado do mercado capitalista deriva da intensa concorrência de capitais dos países capitalistas avançados que, precisamente pelo seu elevado grau de desenvolvimento capitalista, são forçados necessariamente a transpor a disputa para o plano internacional, "em luta pelas condições restantes de acumulação" (MARIUTTI, 2019, p.9)

Mas críticas de Rosa são anteriores a própria Revolução Russa. Em 1904, ela publica “Questões da Organização da Social Democracia Russa” (1991). No livro, Rosa Luxemburgo critica o excesso de centralismo de Lenin, Trotsky e demais revolucionários russos. Para a pensadora, o não desenvolvimento econômico da Rússia faz com que a classe operária não vivencie a experiência democrático-burguesa. Essa falta de prática impede o desenvolvimento espontâneo do caráter revolucionário. A solução dada pelos russos - a formação de uma vanguarda revolucionária ultracentralizada - remete às ideias blanquistas, pois aparta essa vanguarda da luta revolucionária e aciona o risco de se insular uma burocracia que vive para si mesma.

Para Rosa Luxemburgo, a espontaneidade da luta de classes se dá pelo caráter específico da classe trabalhadora na esfera da produção. Para isso, o papel do Partido deve ser o de despertar esse caráter, alimentando-se dele. O Partido deve ser constituído da vontade revolucionária das massas, e não constituir a vontade revolucionária das massas. A organização, o esclarecimento e o processo revolucionário em si não são etapas apartadas da luta de classes, mas elementos orgânicos constituídos de maneira dialética, simultânea. O centralismo verdadeiramente revolucionário depende não só da ampla formação das massas, mas também de mecanismos que garantam a sua participação irrestrita nas esferas do Partido.

Não faltam críticas acerca da perspectiva de Lenin na literatura contemporânea. Para muitos, o centralismo de Lenin culmina no processo autoritário que levaria ao stalinismo e à derrocada da União Soviética, 75 anos depois. A ótica dos anarquistas tende a superar essa visão. Graeber (2014) versou sobre o novo movimento anarquista, orientado para o século XXI. Tratado por antiglobalização, o movimento na verdade é anticapital, tendo em vista que a globalização liberalizou a circulação de capitais entre as fronteiras, não de pessoas. O movimento é violento contra o capital e a propriedade, não contra a vida em geral, algo constantemente confundido quando são tratados por "protestos violentos". Os novos movimentos anarquistas são uma ressignificação do anarquismo dos séculos XIX e XX, visto como antiquado e irrealista depois da vitória bolchevique. No eixo central, todo o anarquismo tem por foco a aplicação da ação direta, a relação intrínseca entre teoria da democracia participativa e atuação prática. A capacidade de formular utopias segue sendo a mola propulsora do anarquismo, que não espera etapas ou confia em vanguardas. 
A discussão entre movimento social marxista-leninista e movimento social anarquista passa pela transição entre hegemonia e afinidade, apresentada por Day (2017). Para além do debate se há continuidade ou ruptura nas relações entre Lenin e Gramsci, o pesquisador buscou uma convergência nas duas formas de pensar a luta social através do ocidente, um misto de coerção e coesão. É a lógica que o autor vai tratar como a dos Velhos Movimentos Sociais, aquela pelo qual existe o objetivo específico de se tomar a hegemonia do "inimigo" para produzir uma hegemonia própria. Para Lenin, esse ataque se dava pela força. Impossibilitado de efetuar o mesmo método no Ocidente, Gramsci propunha a disputa da sociedade civil. Em ambos, a conquista da hegemonia permanece como norte.

Dentro desta forma de visão, Day (2017) apresenta a proposição de que o Estado de BemEstar Social e a suposta mitigação dos conflitos econômicos produziu a necessidade de se enfrentarem novos inimigos, não mais vinculados a esfera econômica. A questão de classe não forma mais o antagonismo fundamental. Pensadores como Laclau e Moffe são apresentados como centrais pelo autor, ao tirar o trabalhador do centro da mudança social e revisitar os limites da teoria gramsciana. Esses novos atores não podem ser enumerados, já que a lista é constantemente atualizada, dentro da perspectiva de se levar a democratização da vida a todas as esferas de convívio social. Quatro aparelhos movem essa transição, na literatura de Laclau: a lógica das demandas que se interconectam e das oposições que se ressignificam; a insuficiência do conceito de hegemonia perante um sujeito revolucionário que nunca será universal, nunca representará a todos; a ascensão de "significantes vazios", que representam coisas diferentes em contextos diferentes e, por último, a generalização das relações humanas, que criam lógica de representação vazias e funcionais apenas no status quo do poder estabelecido. Para Day (2017), estes aspectos demostram como os Novos Movimentos Sociais transitaram de políticas de consenso e coerção para políticas de puro consenso, de adesão liberal. A questão deixa de ser a substituição do Estado e sim a disputada da demanda pontual.

É possível apresentar contraposições substanciais à crítica ao suposto “ultracentralismo" leninista levantado por Luxemburgo e por outros autores. Em primeiro lugar, há uma diferenciação importante a se fazer: todas as críticas de Rosa Luxemburgo ao modelo leninista de organização estão circunscritas em um debate que privilegia a categoria "classe", ao contrário dos demais autores, circunscritos em tradições teóricas que abandonam ou relativizam esta centralidade (em diferentes níveis). Fazendo essa ressalva, podemos apontar uma contradição na crítica de Luxemburgo: ao atribuir ao desenvolvimento de todos os modos de produção uma espécie de "comunismo primitivo originário", justificado à certa "natureza humana" (MARIUTTI, 2019), Luxemburgo permite que, por vezes, seu eixo analítico disponha de certo espontaneísmo tendencial. Como demonstra Mandel (1971), isso a encaminhou a dar excessivo crédito à "educação das massas" sem que houvesse uma forma organizativa que conduzisse na prática esse processo, através da formação de quadros dirigentes. Esse receio produzido pelo medo da burocratização, 
entretanto, não denota em saldo negativo quando posto dialeticamente com o próprio trabalho de Lenin. Ambos lapidaram suas teorias da revolução em processos inovadores e complementares:

Lenin chegou às mesmas conclusões que Rosa sobre a social-democracia alemã em 1914. Ele concluiu que o essencial para o proletariado não é "a organização" pura e simplesmente, mas a organização cujos programa e fidelidade prática, cotidiana, a tal programa, que garantiriam que ela seria uma força propulsora e não um freio ao levante revolucionário das massas. Rosa chegou à mesma conclusão que Lenin quanto à necessidade de uma organização separada da vanguarda revolucionária em 1918, quando ela compreendeu profundamente que era insuficiente ter confiança no ímpeto das massas ou na sua espontaneidade para quebrar o freio dos funcionários social-democratas dali em diante contra-revolucionários. (MANDEL, 1971)

Dentro dos marcos analíticos do objeto aqui presente, a perda de centralidade da questão de classe pode também ser questionada como um valor em si. O próprio Day (2017) versa sobre os "Novíssimos Movimentos Sociais", e suas práticas que absorvem conteúdo tanto dos Velhos, quanto dos Novos Movimentos Sociais. A questão não passaria mais por realizar reformas ou revoluções, e sim em atuar diretamente, tornando redundante o poder Estatal tanto na esfera nacional quanto transnacional. Aqui está a distinção mais importante no texto do autor: a política do ato e a política da demanda. A segunda envolve a cobrança de ações do Estado para situações pontuais. Ela pode desenvolver mudanças na forma como as coisas se dão, mas não mexe nas estruturas pelo qual essas situações são criadas; em longo prazo, culminam em um fortalecimento da existência do próprio Estado. A política do ato, sem a necessidade de uma hegemonia que centralize o enfrentamento, é quem quebra este ciclo, ao propor um modelo de intervenção direta. Nesse modelo, o ativista pode "viver o sonho" de outra sociedade, de outro modo de democracia.

A crise econômica de 2008 tem então papel fundamental nas atuações recentes. No ano de 2011, o mundo foi marcado por grandes manifestações ao redor do globo. Na Espanha, os Indignados tomaram as praças contra a participação do sistema financeiro na política e o crescente desemprego. No Oriente Médio, a chamada "Primavera Árabe" derrubou boa parte dos regimes ali instaurados. Nos Estados Unidos, o Occupy Wall Street tomou conta de Nova Iorque em um amplo protesto contra o sistema financeiro e a atuação dos bancos na tomada de decisão política. "Sentir" a crise foi elemento essencial para o despertar desses protestos. Métricas de organização que fujam da centralização excessiva, muito vinculadas às redes sociais e atuação online também estavam presentes.

O fenômeno também chegou ao Brasil. Junho de 2013 pode ser tratado como o "conjunto de revoltas populares mais importantes da história brasileira recente, não por aquilo que elas produziram, mas por aquilo que elas destruíram" (SAFATLE, 2017, p.107). Iniciadas no início do ano, pelos protestos contra o aumento das passagens em Porto Alegre, culminaram em uma grande revolta motivada pelo aumento de 0,20 centavos na tarifa de ônibus em São Paulo. Os protestos, articulados pelo Movimento Passe Livre (MPL), logo se espalharam por todo o país, agregando 
todo o tipo de pauta e manifestante. Alonso e Ann (2016) apresentam a existência de três repertórios marchando em junho: o repertório socialista, o repertório anarquista e o repertório patriótico. Os manifestantes capturavam muito do que havia acontecido na onda global de protestos e adaptado aos seus repertórios. Neste caso, os repertórios dos Indignados e do movimento Occupy eram incorporados a demandas como os megaeventos esportivos de 2013, 2014 e 2016 e a crise de legitimidade social dos governos do PT, gerada tanto pelas denúncias de corrupção quanto pelo afastamento com as bases sociais. A resposta violenta por parte da polícia também acarretou em ampla adesão aos protestos.

Os repertórios diversos misturam suas táticas ao longo dos protestos. O que os une como massa amorfa é justamente a negação da instituição, nesse caso, representada pelos partidos. Essa repulsa se sustenta, inclusive, através de um discurso altamente moral, como vemos em Weiss (2014). A "falta de pauta" de junho de 2013 causou certo desconforto na comunidade internacional, tendo em vista que o Brasil vivia uma democracia em pleno funcionamento e não fora (ainda) atingido tão diretamente pela crise. A questão é que o afastamento das instituições em relação às pessoas gera certa desconexão entre a teoria democrática e a prática institucional. Um sentimento de "dever ser" é desperto. O contágio com o que acontece ao redor do mundo, alinhado com a sensação de que o Estado brasileiro não opera como deveria, motiva a sensação de solidariedade gerada pela experiência dos protestos.

Como foi observado nesse excerto, é possível extrair muitas reflexões sobre a consciência de classe na luta coletiva através das manifestações globais que ocorreram após a Crise de 2008. Mesmo sem assumir um repertório necessariamente autointitulado de esquerda, houve uma recusa à institucionalidade estabelecida pairando sobre todos os protestos - reconfigurada conforme as demandas nacionais. Essa recusa, amplamente relacionada à crise econômica, encaminhou para uma rejeição à democracia, não como valor, ou como direito, mas como procedimento institucional. A democracia que se resume ao funcionamento das instituições alicerçadas em eleições regulares, marca do Estado capitalista, se mostrou insuficiente em solver os problemas da população ante a crise. O caráter global desse movimento é plenamente identificável com a literatura de Rosa Luxemburgo, como pudemos exemplificar. De maneira por vezes bastante polêmica, a autora defendeu o caráter espontâneo da revolta popular, justificado pelo papel ocupado pela classe trabalhadora na produção capitalista. É esse papel que leva à revolta, e é esse caráter que deve ser preservado pela vanguarda revolucionária: sempre disposta a ser guiada pelas massas, ao invés de guiá-las. Os protestos de 2010, 2011, 2012 e 2013 no mundo todo demonstram o quanto a solidariedade internacional e a importância de se buscar métodos mais horizontais de organização política seguem atuais. 


\section{CONSIDERAÇÕES FINAIS}

Este artigo possui dois eixos de análise. No primeiro, foi possível observar que a socialdemocracia, com um modelo de regulamentação do capitalismo através do Estado, impedindo que as desigualdades sociais alcancem níveis elevados e impedindo a acumulação predatória de capitais, acabou por, em suas insuficiências, formar as bases que transformaram o neoliberalismo em ideologia hegemônica, em uma nova razão de mundo. Essa ideologia neoliberal acabou, por meio de seus próprios marcos de significação, culminando em uma crise global em 2008. O segundo eixo demonstrou que essa crise fomentou uma nova onda de protestos globais, com características singulares. Esses protestos questionavam o capitalismo como um sistema global desigual, eram baseados em um intenso mecanismo e contágio e solidariedade internacional e, sustentados em certa autonomia, questionavam a hegemonia de vanguarda que imperou com modus operanti da contestação pública até então. Esses dois eixos de análise estiveram, através de nossa revisão bibliográfica, presentes como pilares do pensamento de Rosa Luxemburgo no começo do século XX. Isso evidencia, sem dúvida, uma forte atualidade do pensamento da autora, e uma necessidade de que sua obra seja constantemente revisitada, tanto nos debates acadêmicos, quanto nos espaços políticos que tomam como pressuposto a necessidade de superar o capitalismo.

A conjuntura política demonstra, com bastante materialidade, uma relação íntima entre a crise econômica do capital e o crescimento dos protestos no Brasil e ao redor do globo. Esses protestos em muito rompem com as lógicas formais de centralização da política e narrativa pela conquista de uma nova hegemonia, ao invés do rompimento de hegemonias. Essa relação já havia sido estabelecida na bibliografia de Rosa Luxemburgo, que teve, em sua trajetória, preocupação em apontar o quanto o caráter acumulador do capital (e as crises decorrentes dele) aponta para certa espontaneidade da classe trabalhadora em se rebelar. A questão ainda em aberto é se a catástrofe econômica é uma condição dada, ou se existem elementos para que o capital se readapte nessa conjuntura.

* Artigo recebido em 27 de outubro de 2019, aprovado em 17 de fevereiro de 2020.

\section{REFERÊNCIAS}

ALONSO, Angela. Mische, ANN. Changing Repertoires and Partisan Ambivalence in the New Brazilian Protests. Bulletin of Latin American Research, v.1, p. n/a-n/a, 2016.

BOBBIO, Norberto. Liberalismo e Democracia. Brasília: Editora Brasiliense, 1991. 
BORON, Atílio. Estado, Capitalismo e Democracia na América Latina. São Paulo: Paz e Terra, 1991.

DARDOT, Pierre \& LAVAL, Christian. A nova razão do mundo: ensaio sobre a sociedade neoliberal. São Paulo: Boitempo, 2016.

DAY, Richard JF. From hegemony to affinity: The political logic of the newest social movements. Cultural studies, v. 18, n. 5, p. 716-748, 2004.

DELLA PORTA, Donatella \& MATTONI, Alice. Spreading protest: social movements in times of crisis. Colchester: ECPR Press, 2014.

DIAMOND, L. Facing up to the democratic recession. Journal of Democracy. Volume 26, Number 1 January 2015.

FIORI, José Luís. 6o lições dos 90: Uma década de neoliberalismo. Rio de Janeiro: Record, 2001.

FUKUYAMA, F. Por que o desempenho da democracia tem sido tão ruim? Journal of Democracy. Volume 4, Número 2, outubro de 2015

GRAEBER, David. The new anarchists. The New Left Review, v. 13, n. 6, p. 61-73, 2002.

LUXEMBURGO, Rosa. Reforma ou Revolução? São Paulo: Expressão Popular, 2015.

LUXEMBURGO, Rosa. Questões de Organização da Socialdemocracia Russa. In: LUXEMBURGO, Rosa. A Revolução Russa. Petrópolis: Vozes, 1991.

LUXEMbURgo, Rosa. Revolução Russa. in LUXEMbURGO, Rosa. A Revolução Russa. Petrópolis: Vozes, 1991.

MANDEL, Ernest. O Capitalismo Tardio. São Paulo: Abril Cultural, 1982.

MANDEL, Ernest. Rosa Luxemburg et la social-démocratie allemande. Quatrième Internationale, 1971, $\mathrm{nr}$. 48, pp.10-20. Disponível em: <https://teoriamarxista.wixsite.com/blog-mri/post/rosa-luxemburgo-ernest-mandel>. Acesso em: 12/02/2019. Tradução: Pedro Barbosa, Vinicius Souza e Sidarta Landarini.

MARIUTTI, Eduardo Barros. Para além do economicismo: a acumulação de capital na perspectiva de Rosa Luxemburgo. Revista Novos Rumos. v. 56, n. 1, 2019.

MOTA, Leonardo de Araújo e. Capitalismo contemporâneo, desigualdades e a crise de 2008. Revista Brasileira de Desenvolvimento Regional, Blumenau, 1 (1), P. 51-64, Outono de 2013 .

PIKETTY, Thomas. O Capital no Século XXI. Rio de Janeiro: Intrínseca, 2014.

PRZEWORSKI Adam e WALLERSTEIN Michael. O capitalismo democrático na encruzilhada. Novos Estudos, NO$^{\circ} 22$ - outubro de 1988.

RANCIERE, Jacques. Ódio à democracia. São Paulo: Boitempo, 2013.

SAFATLE, Vladimir. Só mais um esforço. São Paulo: Três Estrelas, 2017.

TARROW, Sidney. The Transnational Activism. Cambridge: Cambridge University Press, 2005 . 
WEISS, R. A. As Manifestações Sob a Ótica da Sociologia da Moral. In: CATTANI, Antonio David. (Org.). \#protestos - Análises das Ciências Sociais. Porto Alegre: Tomo, 2014. 